Плодоводство и виноградарство Юга России № 51(03), 2018 г.

УДК 632.2: 634.7: 631.52

UDC 632.2: 634.7: 631.52

DOI: 10.30679 / 2219-5335-2018-3-51-137-145

DOI: 10.30679 / 2219-5335-2018-3-51-137-145

ОЦЕНКА УСТОЙЧИВОСТИ СОРТОВ ЗЕМЛЯНИКИ САДОВОЙ К АНТРАКНОЗНОЙ ЧЕРНОЙ ГНИЛИ В ЮЖНОМ РЕГИОНЕ

Холод Надежда Афанасьевна, канд. биол. наук, доцент

ст. научный сотрудник, лаборатории защиты плодовых и ягодных культур

Кащиц Юлия Петровна, аспирант

мл. научный сотрудник

лаборатории защиты

плодовых и ягодных культур

Федеральное государственное

бюджетное научное учреждение

«Северо-Кавказский научный

федеральный центр садоводства, виноградарства, виноделия»,

Краснодар, Россия

Добренков Евгений Анатольевич, канд. с.-х. наук

директор

Семенова Лариса Григорьевна, канд. биол. наук, доцент вед. научный сотрудник группы плодовых культур

Федеральное государственное бюджетное научное учреждение «Федеральный исследовательский центр Всероссийский институт генетических ресурсов растений имени Н.И. Вавилова» (Майкопская ОС ВИР), Майкоп, Россия

Основной экспериментальный материал для исследований получен путем фитосанитарного мониторинга производственных плантаций Краснодарского края и коллекции генетических ресурсов земляники Майкопской опытной станции ВИР в 20132015 гг. на естественном инфекционном фоне. Объектом исследований являлись

\section{EVALUATION OF STABILITY OF STRAWBERRY VARIETIES TO ANTHRACNOSE BLACK ROT IN THE SOUTHERN REGION}

Holod Nadezhda Afanasyevna

Cand. Biol. Sci., Docent

Senior Research Associate

of Laboratoryof Fruit

and Berry Crops Protection

Kashchits Yulia Petrovna

Post Graduate Student

Junior Research Associate

of Laboratory of Fruit

and Berry Crops Protection

Federal State Budget

Scientific Institution

«North Caucasian Federal

Scientific Center of Horticulture,

Viticulture, Wine-making»,

Krasnodar, Russia

Dobrenkov Eugeniy Anatolyevich

Cand. Agr. Sci.

Director

Semenova Larisa Grigoryevna

Cand. Biol. Sci., Docent

Leading Research Associate

of Fruit Crops Group

Federal State Budget

Scientific Institution

«Federal Research Center

All-Russian Institute of Plant Genetic

Resources named after N.I. Vavilov»

(Maikop ES VIR), Maikop, Russia

The main experimental material for research was obtained through the phytosanitary monitoring of industrial plantations of the Krasnodar Territory and a collection of genetic strawberry resources in the Maikop Experimental Station of VIR in 2013-2015 on natural infectious background. The object of research were more than 400 
более 400 сортообразцов земляники садовой отечественной и мировой селекции.

В результате проведенного

фитосанитарного мониторинга земляничных плантаций южного региона повсеместно выявлено поражение растений сортов Азия, Клери, Альба, Роксана, Хоней антракнозной черной гнилью. Эти сорта в разные годы, начиная с 2003 г., были завезены из Италии. В настоящее время не выявлено сортов и форм земляники, иммунных к антракнозу, однако сорта различаются по степени устойчивости к этому заболеванию. Причем сорта, устойчивые к одним штаммам гриба, могут поражаться другими штамами грибов. Фитосанитарный мониторинг показал, что в 2013году на коллекции генетических ресурсов земляники Майкопской ОС ВИР высажено четыре сорта (Азия, Альба, Роксана, Хоней), зараженных антракнозной черной гнилью, а 2015 году из более 400 сортообразцов болезнью были поражены 198 , что составляет $50 \%$ от общего количества. Учитывая скрытую форму болезни в течение нескольких лет, предположительно на сегодняшний момент заражены все 100 \% сортообразцов земляники садовой. В результате проведенной нами полевой оценки степени поражения земляники антракнозной черной гнилью не было выделено устойчивых к болезни сортообразцов, которые могли бы быть исходным материалом, перспективным для их использования в дальнейших селекционных исследованиях.

Ключевые слова: СОРТА, ЗЕМЛЯНИКА САДОВАЯ, АНТРАКНОЗНАЯ ЧЕРНАЯ ГНИЛЬ, УСТОЙЧИВОСТЬ strawberry varieties by domestic and foreign breeding. As a result of phytosanitary monitoring of strawberry plantations in the Southern Region, the damage of Asia, Clery, Alba, Roxana, and Honey plants with anthracnose black rot was widely recognized. These varieties for different years, since 2003, were imported from Italy. At present, there are no strains and forms of strawberry immune to anthracnose, but the varieties differ in the degree of resistance to this disease. Moreover, the varieties that are resistant to the some strains of the fungi can be affected by other strains of fungi. Phytosanitary monitoring showed that in 2013, four varieties (Asia, Alba, Roxana, Honey), infected with anthracnose black rot, were planted in the collection of genetic strawberry resources of the Maikop ES of VIR, and 198 out of more than 400 varieties were affected in 2015 , which is $50 \%$ of the total. Taking into account the latent form of the disease for several years, presumably now all $100 \%$ of the strawberry strains are infected. As a result of our field assessment of the degree of strawberry defeat by anthracnose black rot, we did not isolate the disease resistant varieties, which could be the initial material, promising for their use in further breeding study.

Key words: VARIETIES, STRAWBERRY, ANTHRACNOSE BLACK ROT, STABILITY

Введение. Земляника садовая является высокоадаптивной, скороплодной и урожайной культурой, которая занимает ведущее место среди ягодных культур, возделываемых в южном регионе. Современные сорта земляники садовой, наряду с высоким потенциалом продуктивности, должны обладать устойчивостью к биотическим стрессорам, в частности к гриб- 
Плодоводство и виноградарство Юга России № 51(03), 2018 г.

ным болезням. Поражение земляники различными микозами приводит к нарушению физиологических процессов, и, как следствие, снижению урожайности насаждений. В связи с возрастающими требованиями к экологической безопасности продукции и окружающей среде устойчивость растений земляники к вредителям и болезням приобретает первостепенное значение. Использование в качестве родительских форм сортов и форм, обладающих высокой степенью устойчивости к вредным организмам, повышает вероятность выделения в их потомстве высокоустойчивых гибридов.

К числу наиболее вредоносных заболеваний земляники в условиях юга России в последние годы относится антракнозная черная гниль. относительно недавно обнаруженная, но уже распространённая по всему миру. В Краснодарском крае антракнозная черная гниль впервые была выявлена нами в 2005 году: на плантациях земляники было отмечено массовое поражение ягод. Болезнь завезена с посадочным материалом из Италии в 2003 году [1, 2]. Потери от нее нередко достигают 80 \% урожая, а выпады растений в маточных насаждениях - 1/3 и более. С 1993 года антракноз стал карантинной болезнью в Европе и Средиземноморье [3]. Заболевание опасно тем, что после заражения растений может очень длительное время никак не проявлять себя. Именно с такими бессимптомными растениями и произошло быстрое расселение антракноза земляники по всему миру.

Антракнозом поражаются практически все органы растений земляники садовой. На усах и в верхней части черешков молодых развернувшихся листьев возникают мелкие продолговатые, вдавленные, красно-бурые, затем черные язвы. Сливаясь, они окольцовывают орган, вследствие чего соответствующие листья, розетки или все растение увядают и засыхают. На листовых пластинках наблюдается множество светло-бурых, затем чернеющих пятен диаметром 0,5-2,0 мм. Могут возникать V-образные темно-бурые сектора вдоль жилок к краям листьев, сходные с таковыми при поражении фомопсиозной или гномониозной пятнистостями (рис. 1). 


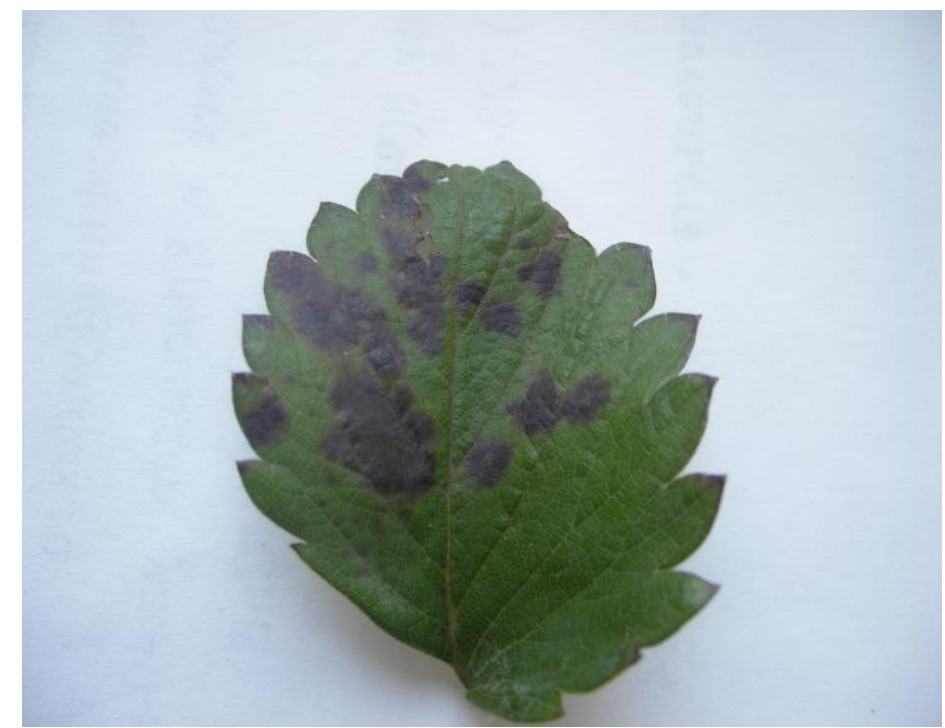

Рис. 1. Лист земляники садовой, пораженный антракнозной черной гнилью

Плоды поражаются на всех стадиях развития с образованием бронзово-бурых, затем чернеющих, округлых несколько вдавленных пятен твердой, сухой гнили (рис.2). На зрелых ягодах первоначальное пятно может выглядеть как одна потемневшая семянка.

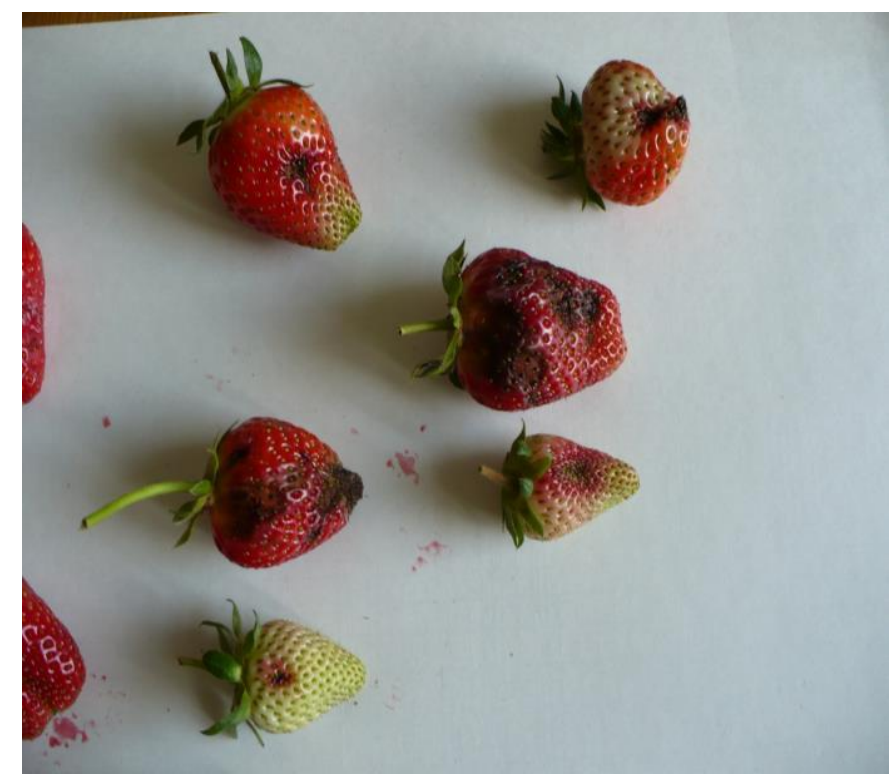

Рис. 2. Ягоды земляники садовой, пораженные антракнозной черной гнилью

Поражение распространяется в виде конуса до глубины 1 см, расширяется и принимает вид "вдавленности от большого пальца", а затем охватывает всю ягоду. Во влажных условиях вокруг семянок развиваются 
Плодоводство и виноградарство Юга России № 51(03), 2018 г.

клейкие слизистые, лососевого, а затем черного цвета скопления конидий с пушистым розовым мицелием по краям. На перезрелых плодах возникают вдавленные, сморщенные, мокнущие, цвета шоколада с молоком, позднее некротизирующиеся пятна. Пораженные цветки отмирают, на листьях проявляется характерная черная пятнистость, сердцевина рожка краснеет.

Гриб-возбудитель может выживать в почве и остатках растений до 69 месяцев в умеренном климате, но в тропиках и субтропиках быстро погибает [4]. Помимо рассады и других растительных материалов C. acutatum распространяется на руках сборщиков ягод, их одежде и обуви, орудиях производства, транспорте, с разносимыми ветром водяными брызгами, насекомыми [5, 6, 7]. Так, в 2012 году на плантации ЗАО ОПХ «Центральное» (Краснодар) был заражен болезнью сорт земляники Ароза, через год произошло перезаражение рядом расположенного сорта Эльсанта. Распространение анртракнозной черной гнили на данном сорте составило $100 \%$ при интенсивности развития C. acutatum 30-50 \% [8, 9].

Болезнь вызывают не менее 5 видов из рода Collettotrichum, относящихся к высшим несовершенным грибам подтипа Deuteromycotina отряда Melanconiales семейства Melanconiaceae. Важнейшим из них является многоядный Colletotrichum acutatum Simmonds, объявленный объектом карантина Европейско-Средиземноморской организацией по защите растений. Потенциальную опасность представляет космополитический многоядный вид C. dematium (Pers. Ex Fr.) Glove, отмеченный на землянике только в США, и полиморфный, распространенный на землянике в тропических и субтропических регионах мира C.gloeosporioides (Penz) Penz et Sacc. Однако на других культурах он встречается по всему миру, включая и Россию.

C. acutatum на искусственных питательных средах образует серый до бурого мицелий, с погруженными розовато-серыми хламидоспорами. Под кожицей ягод возникают спороложа-ацервули. Позднее они разрывают кожицу и обнажают короткие, цилиндрические, прозрачные или буроватые 
Плодоводство и виноградарство Юга России № 51(03), 2018 г.

конидиеносцы, несущие цилиндрические конидии с заостренными концами, размерами 8-18х3-4,5 мкм [10].

Зимуют мицелий и хламидоспоры в тканях и остатках растений, почве. Образующиеся весной конидии с брызгами воды заносятся на листья, цветки и плоды, а также разносятся ветром, насекомыми, орудиями труда, пальцами сборщиков, с ягодами и тарой. Основное расселение C. Acutatum происходит с рассадой. Заражение тканей происходит быстро при 24-28 ${ }^{\circ} \mathrm{C}$ и 100 \% относительной влажности. В условиях умеренного климата болезнь опасна для пленочных туннелей, в дождливое, но жаркое лето - преимущественно для нейтральнодневных и ремонтантных сортов земляники.

Объекты и методы исследований. Основной экспериментальный материал для исследований получен путем фитосанитарного мониторинга производственных плантаций Краснодарского края и коллекции генетических ресурсов земляники ВИР (Майкопской ОС ВИР) в 2013-2015 гг. на естественном инфекционном фоне. Материалом исследований являлись более 400 сортообразцов отечественной и мировой селекции. Использовались стандартные методики выявления и учета болезней ягодных культур [11-14].

Обсужнение результатов. В результате проведенного фитосанитарного мониторинга земляничных плантаций южного региона повсеместно выявлено поражение растений культуры сортов Азия, Клери, Альба, Роксана, Хоней антракнозной черной гнилью. Эти сорта в разные годы, начиная с 2003 г., завезены из Италии. В настоящее время не выявлено сортов и форм, иммунных к антракнозу, однако имеются сорта, с различной степенью устойчивости к заболеванию. Причем сорта, устойчивые к одним штаммам гриба, могут поражаться другими штаммами [15].

Исследованиями установлено, что в 2013 году на коллекции генетических ресурсов земляники ВИР (Майкопской ОС ВИР) было высажено четыре сорта (Азия, Альба, Роксана, Хоней), зараженных антракнозной 
Плодоводство и виноградарство Юга России № 51(03), 2018 г.

черной гнилью, а в 2015 году из более 400 сортообразцов болезнью были поражены 198, что составляет 50 \%. Учитывая скрытую форму болезни в течение нескольких лет, предположительно на данный момент заражены все $100 \%$ сортообразцов.

Антракнозной черной гнилью поражены следующие сортообразцы земляники: Кубанская ранняя, Восток, Восход, Луч, Финиковая, Иосиф Магомед, Украина, Киянка, Коралловая-32, Запашна, Елшанка, Любовь Поволжья, Ударница, Бирюлевская ранняя, Аэлита, Обильная, Пионерка, Подарок весны, Дружба, Ленинградская ранняя, Ленинградская поздняя, Павловская красавица, Поздняя из Павловска, Протем, Гренадир, Гардсман, Клаймекс, Албриттон, Фресно, Алисо, Тайога, Блекмон, Эмпайр, Спаркл, Кетскилл, Мидуэй, Редглоу, Джерсибелл, Клермонт, Шуэкроп, Шарплесс, Успех, Хаверланд, Ред Пур, Ред Чив, Эрлибелл, Шаксен, Виктория, Индийская, Кембридж Фейворит, Кембридж Вигор, Ворка плодородная, Георг Зольтведель, Люцида Перфекта, Мице Шиндлер Зигер, Дойч Эверн, Зенга Зенгана, Доктор Эфем, Хумми Гранде, Хумми Триска, С-ц Ротер Диамонт, Дрезден, Горожанин, Идун, Зефир, Мадам Муто, Бэль-ЭБон, Ранняя Мускатная, Сан Реваль, Фертилити, Мари Франц, 5491, Эл. $77-$ 9-6, Гибрид-20/2, Холидей, Тракторист, Стоплайд, Сокол, Славутич, Соловушка, Зенга Зенгана, Алена, Шведская, Пандора, Предгорная МОС ВИР, Абадзехская, Лаба, Джем, Салана, Шаста, Арома, Фейерверк, Покахонтас, Веспер, Стилмастер, Мидленд, Кульвер, Редстар, Секвойя, Гардиан, Инга, Вола, Гласса, Горелла, Мертон Роузи, Талисман, Редгаунтлет, Моя любимица, Сюрприз де Голя, Сувенир Ч. Махерауха, Зибель, С-Ц Чудо Трюфо, С-ц фирмы Боулей, Кл - 37, Болгарская красавица Эл. 11-1-4, Эл. 21-227, Эл. 9-5-12, Кл - 32, Кл-12, Кл-42, Кл-11а, Шуэкроп х Мд из 3919, Гибрид - Обильная х Джерсибелл, Гибрид - 63, Гибрид -15, Гибрид 298-6-16, Гибрид из 37-73, Гибрид из 11-3, Баунти, Полка, Кармен, Избранница, Дукат Бондурелла, Профьюжен, Кардинал, Пегас, Венгерка крупноплодная, Коррадо, Гера, Боровицкая, , Сюрприз Олимпиаде, Калинка, Универсал-1, 
Белая ананасная, Веспер, Фракунда, Золушка Кубани, Алая, Женева, Зефир, Редгаундлет, Тейнира, Таврическая, Былинная, Лорд, Хусейн Магомед Али, Герман, Корона, Царскосельская, Онега, Хоней, Дивная, Слонёнок, Фертоди Корай, Витязь, Добрыня, Кент, Моллинг Пандора, Цунаки, Фейерверк, Урожайная ЦГЛ, Белруби, Елизавета II, Богота, Эльсанта, Без названия, Уралочка розовая, Руслан, Роксана (НИКА), Хоней (НИКА), Альба (НИКА), Азия (НИКА), Польская, Незнакомка, Троицкая, Сара, Маришка, Эйви-2, Эльсанта, Майя, Онда, Дарселект, Мармолада, Ирма, Флоренс, Клери, Зенкора, Симфония.

Bbывоbl. Таким образом, в результате полевой оценки степени поражения растений земляники антракнозной черной гнилью в коллекции Майкопской ОС ВИР не выделено устойчивых к болезни сортообразцов, которые могли бы служить исходным материалом, перспективным для использования в дальнейшей селекции.

\section{Литература}

1. Холод, Н.А. Антракноз садовой земляники / Н.А. Холод, О.З. Метлицкий, С.Е. Головин, И.А. Ундрицова // Агро XXI. - 2007. - № 4-6. - С. 51.

2. Холод, Н.А. Фитосанитарное состояние земляничного агроценоза в условиях юга России / Н.А. Холод // Защита растений. - 2013. - № 10 - С. 28-30.

3.Denoyes B., Baudry A., Species identification and pathogenicity study of French Colletotrichum strains isolatet from strawberry using morphological and cultural charachteristica. //Phytopathology. 1995. Vol. N 1.

4. Bonde M.R., Peterson G.L. Maas J.L. I coenzyme comparisons for identification of

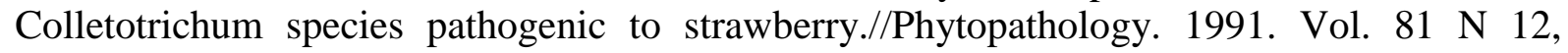
P. 1523-1528.

5. Bonde M.R., Peterson G.L., Maas J.L. I coenzyme comparisons for identification of Colletotrichum species pathogenic to strawberry. //Phytopathology - 1991. Vol. 81 № 12, P. 1523-1528.

6. Cook R.T.A. Strawberry black spor caused by Colletotrichum acutatum. // Plant Healthy. 1994. European Single Market. BCPC Monograf. 1994. № 54. P. 301-304.

7. Paulus A.O. Fungal diseases of strawberry. //Hort. Science. 1990. Vol. 25. № 8. P. 885-889.

8. Холод, Н.А. Совершенствование системы управления микозами корней в земляничном агроценозе / Н.А. Холод, Л.А. Пузанова, К.В. Метлицкая // Плодоводство и ягодоводство России. Сб. научн. работ ГНУ ВСТИСП. - Т. 36, Ч. 2. - М., 2013. - С. 301-305.

9. Холод, Н.А. Современное фитосанитарное состояние насаждений земляники / Н.А. Холод, Л.А. Пузанова, К.В. Метлицкая. // Плодоводство и ягодоводство России. Сб. научн. работ ГНУ ВСТИСП. - Т. ХХІХ, Ч. 2. - М., 2012. - С. 236-242.

10. Метлицкий, О.3. Методические указания по борьбе с гнилями ягод земляники / О.З. Метлицкий, И.А. Ундрицова, Н.А. Холод. - М., 2003. - 73 с. 
11. Метлицкий, О.3. Методические указания по мониторингу вредителей и болезней и системе мер борьбы с ними в маточных и промышленных насаждениях земляники садовой / О.З. Метлицкий, А.С. Зейналов, И.А. Ундрицова, Н.А. Холод - М., 2005. - 111 с.

12. Методика выявления и учета болезней плодовых и ягодных культур. М.: Колос, 1971. - 23 с.

13. Хохрякова, Т.М. Методические указания по сравнительной устойчивости плодово-ягодных культур к основным заболеваниям / Т.М. Хохрякова, Д.М. Кабахидзе, К.В. Никитина [и др.]. - Л., 1968. - 67 с.

14. Холод, Н.А. Болезни земляники / Н.А. Холод // Методические указания по фитосанитарному и токсикологическому мониторингам плодовых пород и ягодников. Краснодар, 1999. - С. 26-30.

15. Scott D.H., Lawrence F.J. Strawberries. Abvances in Fruit Breeding /Eds. Junik J., Moore J.N. // N.Y. Univ. press, 1975- 71p.

\section{References}

1. Holod, N.A. Antraknoz sadovoj zemljaniki / N.A. Holod, O.Z. Metlickij, S.E. Golovin, I.A. Undricova // Agro HHI. - 2007. - № 4-6. - S. 51.

2. Holod, N.A. Fitosanitarnoe sostojanie zemljanichnogo agrocenoza v uslovijah juga Rossii / N.A. Holod // Zashhita rastenij. - 2013. - № 10 - S. 28-30.

3. Denoyes B., Baudry A., Species identification and pathogenicity study of French Colletotrichum strains isolatet from strawberry using morphological and cultural charachteristica. //Phytopathology. 1995. Vol. N 1.

4. Bonde M.R., Peterson G.L. Maas J.L. I coenzyme comparisons for identification of Colletotrichum species pathogenic to strawberry.//Phytopathology. 1991. Vol. 81 N 12, P. 1523-1528.

5. Bonde M.R., Peterson G.L., Maas J.L. I coenzyme comparisons for identification of Colletotrichum species pathogenic to strawberry. //Phytopathology -1991 . Vol. 81 № 12, P. 1523-1528.

6. Cook R.T.A. Strawberry black spor caused by Colletotrichum acutatum. // Plant Healthy. 1994. European Single Market. BCPC Monograf. 1994. № 54. R. 301-304.

7. Paulus A.O. Fungal diseases of strawberry. // Hort. Science. 1990. Vol. 25. № 8. R. 885-889.

8. Holod, N.A. Sovershenstvovanie sistemy upravlenija mikozami kornej v zemljanichnom agrocenoze / N.A. Holod, L.A. Puzanova, K.V. Metlickaja // Plodovodstvo i jagodovodstvo Rossii. Sb. nauchn. rabot GNU VSTISP. - T. 36, Ch. 2. - M., 2013. - S. 301-305.

9. Holod, N.A. Sovremennoe fitosanitarnoe sostojanie nasazhdenij zemljaniki / N.A. Holod, L.A. Puzanova, K.V. Metlickaja. // Plodovodstvo i jagodovodstvo Rossii. Sb. nauchn. rabot GNU VSTISP. - T. HHIH, Ch. 2. - M., 2012. - S. 236-242.

10. Metlickij, O.Z. Metodicheskie ukazanija po bor'be s gniljami jagod zemljaniki / O.Z. Metlickij, I.A. Undricova, N.A. Holod. - M., 2003. - 73 s.

11. Metlickij, O.Z. Metodicheskie ukazanija po monitoringu vreditelej i boleznej i sisteme mer bor'by s nimi v matochnyh i promyshlennyh nasazhdenijah zem ljaniki sadovoj / O.Z. Metlickij, A.S. Zejnalov, I.A. Undricova, N.A. Holod - M., 2005. - 111 s.

12. Metodika vyjavlenija i ucheta boleznej plodovyh i jagodnyh kul'tur. - M.: Kolos, 1971. $-23 \mathrm{~s}$.

13. Hohrjakova, T.M. Metodicheskie ukazanija po sravnitel'noj ustojchivosti plodovojagodnyh kul'tur k osnovnym zabolevanijam / T.M. Hohrjakova, D.M. Kabahidze, K.V. Nikitina [i dr.]. - L., 1968. - 67 s.

14. Holod, N.A. Bolezni zemljaniki / N.A. Holod // Metodicheskie ukazanija po fitosanitarnomu i toksikologicheskomu monitoringam plodovyh porod i jagodnikov. - Krasnodar, 1999. - S. 26-30.

15. Scott D.H., Lawrence F.J. Strawberries. Abvances in Fruit Breeding /Eds. Junik J., Moore J.N. // N.Y. Univ. press, 1975- 71p. 